\title{
LINEAR SPECTRAL UNMIXING OF SENTINEL-3 IMAGERY FOR URBAN LAND COVER - LAND SURFACE TEMPERATURE (LST) ANALYSIS: A CASE STUDY OF METRO MANILA, PHILIPPINES
}

\author{
C. Cruz ${ }^{1}$, A. C. Blanco 2 J. Babaan ${ }^{1}$, J. A. Cruz ${ }^{1}$, R. R. Sta. Ana ${ }^{1}$ E. Paringit ${ }^{2}$ \\ ${ }^{1}$ Training Center for Applied Geodesy and Photogrammetry, University of the Philippines Diliman, Quezon City 1101, \\ Philippines - cacruz7@ up.edu.ph, jbbabaan@gmail.com, johndrew.cruz@gmail.com, raasdafsa@gmail.com \\ ${ }^{2}$ Department of Geodetic Engineering, College of Engineering, University of the Philippines Diliman, Quezon City 1101, \\ Philippines - acblanco@up.edu.ph
}

\section{Commission IV}

KEY WORDS: urbanization, urban heat island, land cover fractions, land surface temperature, remote sensing

\begin{abstract}
:
The advancement of remote sensing technologies is a huge advantage in various environmental applications including the monitoring of the rapid development in an urban area. This study aims to estimate the composition of the different classes (vegetation, impervious surfaces, soil) in Metro Manila, Philippines using a 300-meter spatial resolution Sentinel-3 Ocean and Land Colour Instrument image. The relationship between these land cover fractions with the spatial distribution of land surface temperature at this scale is evaluated. Sentinel-3 image has a higher spectral resolution (i.e. 21 bands), as compared with other Landsat and Sentinel missions, which is a requirement for an accurate cover mapping. Linear Spectral Unmixing (LSU), a subpixel classification method, was employed in identifying the fractional components in the image based on their spectral characteristics. Field survey using spectroradiometer was conducted to acquire spectral signatures of an impervious surface, vegetation, and soil which were used as the endmembers in the unmixing process. To assess the accuracy of the resulting vegetation fractional image, this was compared with a separate land cover pixel-based classification result using a 3-meter high spatial resolution PlanetScope image and with another vegetation index product of Sentinel-3. The results indicate that the recently available Sentinel-3 image can accurately estimate vegetation fraction with $\mathrm{R}^{2}=0.84$ and 0.99 , respectively. In addition, the land surface temperature (LST) retrieved from Climate Engine is negatively correlated with the vegetation fraction cover $\left(R^{2}=0.81\right)$ and positively correlated with the impervious surface fraction cover $\left(R^{2}=0.66\right)$. Soil, on the other hand, has no correlation with the LST.
\end{abstract}

\section{INTRODUCTION}

Worldwide urbanization rate increase in the recent decades has led to various consequences, particularly in sustainable urban development such as the significant reduction of agricultural lands, infrastructure planning, and extensive urban sprawls (Maktav, Erbek, \& Jürgens, 2005). This highlights the need for systematic monitoring of the changes in urban landscapes, as well as its detrimental impacts to the environment, one of which is the substantial rise in land surface temperature within highlyurbanized and rapidly urbanizing cities due to the conversion of vegetated areas and bare soil to impervious surfaces such as buildings and roads. A study by (Tiangco, Lagmay, \& Argete, 2008) revealed that Metro Manila, the largest urban agglomeration in the Philippines, experiences urban heat island (UHI) effect, wherein warmer temperatures are observed in urban areas compared to its surrounding rural areas.

With constant technological progress leading to higher spatial, spectral, and temporal resolution non-commercial satellite imagery such as the recently launched Sentinel-3 Earth observation satellite constellation, remote sensing of the urban landscape is becoming more common as an alternative to traditional surveying. In addition, utilizing remote sensing data for urban applications is preferred because of its capability to cover larger areas in a shorter amount of time (e.g. a Landsat 8 scene covers a $170 \mathrm{~km}$ x $185 \mathrm{~km}$ area), and consistent periodical data can be easily accessed for frequent monitoring of alterations in urban area composition. However, often the case with noncommercial satellite imagery, higher temporal resolution results in a coarser spatial resolution. This makes balancing the two resolutions necessary when selecting the imagery to be used and in some cases, requires the application of additional image processing methods since urban landscapes are composed of various land cover types and building elements with different spatial attributes (Maktav et al., 2005).

Image classification methods for land cover mapping and analysis can be categorized into three main groups namely, pixelbased, object-based, and sub-pixel. In pixel-based classification, only the spectral properties of individual pixels being classified are considered while in object-based classification, pixels are grouped into homogeneous objects based on their spatial and spectral information before applying different classification algorithms (Aggarwal \& Dutta, 2016; Sibaruddin, Shafri, Pradhan, \& Haron, 2018). A problem often encountered when doing pixel-based or object-based classification is the presence of mixed pixels. One method of mitigating the effects of this is by applying sub-pixel classification. With this type of classification, each pixel is not assigned to only one land cover class. Instead, the proportion of each land cover class in the pixel is determined. Studies show that linear spectral unmixing, one of the widely used sub-pixel classification approaches, is capable of improving forest cover estimation accuracy (Bai, Lin, Sun, Mo, \& Yan, 2012) and impervious surface mapping in urban and suburban areas (Yang \& He, 2017)

In this study, the objectives are to (1) estimate relative abundances of urban vegetation, impervious surface, and soil from Sentinel-3 image by applying linear spectral unmixing 
(LSU), and (2) evaluate the relationship between these fraction images and the spatial distribution of land surface temperature.

\section{METHODOLOGY}

The overall methodology used includes three general steps (Fig.1): (1) in-situ collection of endmember spectra, (2) processing of remotely-sensed datasets, and (3) validation and analysis to determine the relationship between LST and fraction images.

\section{FIELD SPECTRAL MEASUREMENT SURVEY}

- Collection of spectral signatures of the three endmembers vegetation, impervious surface, and soil

\begin{tabular}{|c|c|}
\hline & $\begin{array}{l}\text { REMOTE SENSING IMAGE PROCESSING } \\
\text { Sentinel-3 Level } 1 \text { image: land cover abundance estimation } \\
\text { using linear spectral unmixing } \\
\text { PlanetScope image: land cover classification using pixel- } \\
\text { based approach } \\
\text { Landsat-8 image: land surface temperature retrieval } \\
\text { Sentinel-3 Level } 2 \text { image: retrieval of a vegetation index } \\
\text { (OGVI) }\end{array}$ \\
\hline$\bullet$ & $\begin{array}{l}\text { VALIDATION AND ANALYSIS } \\
\text { Correlation between relative abundance of vegetation derived } \\
\text { from Sentinel-3 image and vegetation percent cover classified } \\
\text { using PlanetScope image } \\
\text { Correlation between relative abundance of vegetation derived } \\
\text { from Sentinel-3 image and OGVI values } \\
\text { Correlation between LST and land cover (i.e., vegetation, } \\
\text { impervious, soil) fraction images } \\
\text { Per-city and per-barangay analyses using Zonal Statistics }\end{array}$ \\
\hline
\end{tabular}

Figure 1. Flowchart of the methodology used in this study

\subsection{Study Area}

Metro Manila is the largest conurbation in the country located in the southwestern part of Luzon (Fig. 2). It is composed of sixteen cities and one municipality, covering a total area of 63,600 hectares which is about $0.2 \%$ of the total area of the Philippines. This is known to be the National Capital Region. It ranked 2nd in the most populous region in the country. The most populous cities in the region are Quezon City, Manila, Parañaque, Caloocan, and Taguig. Furthermore, the average population density at national level is 260 people per sq. km., but, Metro Manila has 15,617 persons per sq. km. (Ragragio, 2000).

It also houses some of the largest shopping malls in the world, hotels, commercial spaces, central business districts, subdivisions, national government offices, and even mixed-use developments owned by private corporations. In these areas, the construction materials are mostly concrete, bricks, and glass. This is also where the big universities were established. However, Metro Manila also accommodates large informal settlement communities. They can be found along rivers, creeks, garbage dumps, along railroad tracks, and under the bridges. With regard to the materials used in the slum housing, they are salvaged materials which are mostly GI sheets, tarpaulins, cartons, bamboo sticks, and some are concrete.

In $1996,75.8 \%$ of the region's area was classified as alienable and disposable, while the remaining $24.2 \%$ was classified as forest lands (Ragragio, 2000). Forestlands include fishponds, timberlands, national parks, and unclassified lands. Aside from the numerous establishments in the metropolis, there are still areas which are filled with vegetation. Some of these are the La Meso Ecopark, Ninoy Aquino Parks and Wildlife, and UP Diliman in Quezon City, Las Piñas-Parañaque Critical Habitat and Ecotourism Area, Arroceros Forest and Rizal Park in Manila. Metro Manila is composed of varied land use, making it fit for mapping of different land cover and surface types.

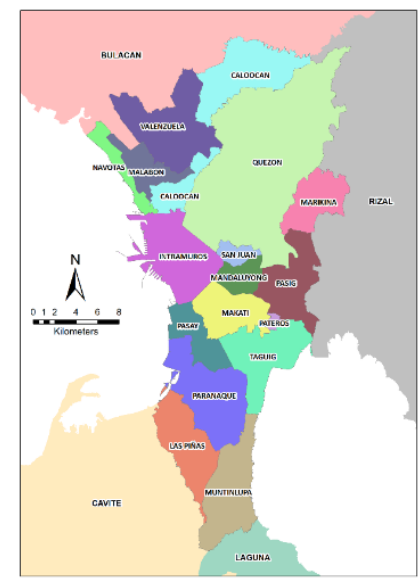

Figure 2. Map of cities in Metro Manila with the surrounding provinces (East: Rizal, North: Bulacan, South: Cavite and Laguna)

\subsection{Field Spectral Measurement Survey}

Field survey was conducted to obtain the spectral signatures of vegetation, soil, and impervious surface in an area. The field survey was scheduled on a day when the sky was generally clear, and between 10:00 AM and 2:00 PM. These conditions were set to minimize the error due to high atmospheric influence and noise (McCoy, 2005).

The instrument set up (Fig. 3) was composed of ASDFieldspec spectroradiometer with spectral range from 350 to 2500 nanometers, battery, toughbook used as the logger, fiber optical cable, and a reference panel.

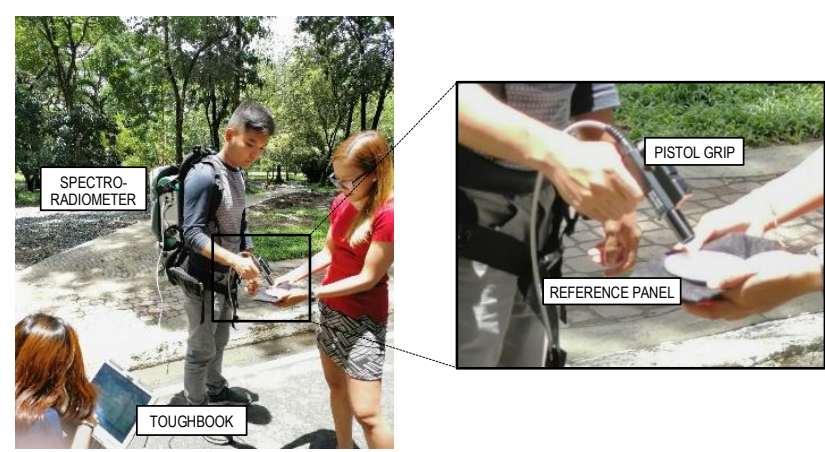

Figure 3. Survey team measuring spectral signature using ASD spectroradiometer

The $\mathrm{RS}^{3}$ software was installed and configured in the laptop. It served as the controller of the instrument in taking the measurements. The ASD Fieldspec Spectroradiometer measures the optical energy that is reflected, absorbed into, or transmitted through a sample. A pistol grip was attached to the fiber optical cable, and the 8-degree field of view was used for the entire fieldwork. 
All measurements were done such that each surface being measured was exposed to direct sunlight. The pistol grip was positioned approximately 45 degrees above the target, so long as it did not cause any shadow over the target material.

Dark current measurement was performed to warm up the instrument. It was done to obtain a more accurate light measurement. White reference measurements were taken before sampling to adjust the measurement to a known standard, thus, $\mathrm{RS}^{3}$ could compute the reflectance for the material being sampled. The instrument was optimized before collecting the data to the proper settings for the light source to be used in the acquisition. It was set that there would be five files per material to be saved in the computer logger with the interval of 1 second in between saves.

$\mathrm{RS}^{3}$ displayed measurements in raw digital numbers plotted against wavelength in nanometer. ViewSpecPro software was used in the post-processing of the spectra files that were produced in the sampling.

\subsection{Image Pre-processing}

The remote sensing datasets used in this study were those satellite images acquired by Sentinel and PlanetScope sensors (Table 1).

Sentinel-3 is a multi-instrument Earth observation satellite constellation developed by the European Space Agency (ESA) for the systematic monitoring of the Earth's surface and atmosphere. Launched in February 2016, its first satellite (Sentinel-3A) is equipped with both optical and microwave sensors: Ocean and Land Colour Instrument (OLCI), Sea and Land Surface Temperature Radiometer (SLSTR), Synthetic Aperture Radar Altimeter (SRAL), and Microwave Radiometer (MWR) (Cornara, Pirondini, \& Palmade, 2017). Among these instruments, only Sentinel-3 OLCI is capable of measuring the spectral characteristics of land and ocean surfaces.

Sentinel-3 OLCI has a full spatial resolution of 300 meters, a revisit time of 2 days, and consists of 21 spectral bands, with wavelengths ranging from visible to infrared region $(400 \mathrm{~nm}$ to $1020 \mathrm{~nm}$ ). Although it has a lower spatial resolution, it is superior in terms of spectral resolution as compared with other opensource multispectral satellite imagery such as Landsat 8 OLI (i.e. 30 meters, 9 spectral bands, 16-day revisit time) and Sentinel-2 MSI (i.e. 10, 20, and 60 meters, 13 spectral bands), which is essential in distinguishing various land cover classes. Wang et al. (2019) successfully applied unsupervised sub-pixel classification of different land surface water bodies using OLCI-acquired images, with overall accuracies ranging from 87 to $91 \%$.

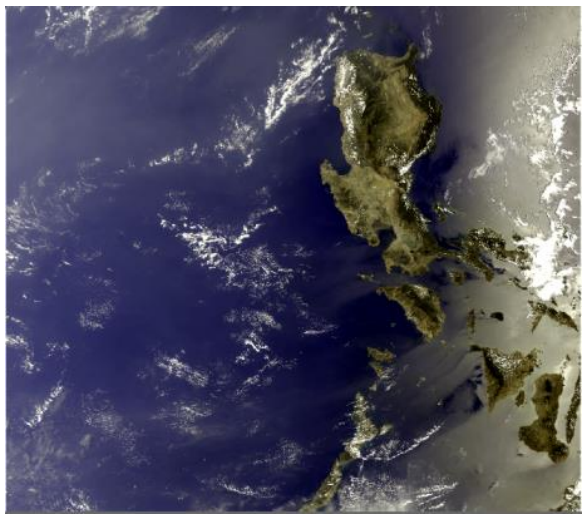

Figure 4. Radiometrically-calibrated Sentinel-3 OLCI true color image of Metro Manila acquired on 25 April 2019
For the study, a Sentinel-3 OLCI Level-1 (top-of-atmosphere radiance) satellite image of Metro Manila, Philippines (Fig. 4) was downloaded online from the Copernicus Open Science Hub (https://scihub.copernicus.eu/) for the sub-pixel classification.

\subsection{Estimation of Relative Abundances of Vegetation, Impervious, and Soil}

Sentinel-3 satellite image was initially corrected for its atmospheric and geometric errors using iCOR, a plugin of ESA Sentinels Application Platform (SNAP) software. SNAP, a free and open-source software, is used in processing Sentinel series missions to produce higher quality of outputs. This resulted to a surface reflectance image consisted of 16 spectral bands only removing the absorption bands. Then, the water bodies were masked out from the image by using the Normalized Difference Water Index method with the formula as follows:

$$
N D W I=\frac{\text { Green }-N I R}{\text { Green }+N I R}
$$

where

$$
\begin{aligned}
& \text { NDWI = Normalized Difference Water Index } \\
& \text { Green = Reflectance measured in a green band } \\
& \text { NIR = Reflectance measured in a near-infrared } \\
& \text { band }
\end{aligned}
$$

Afterward, a sub-pixel classification was applied to determine the relative abundance of each land cover class in the image. For this type of classification, the value of a single-pixel is a combination of the radiances of different materials covered in that particular pixel. In this study, three categories of endmembers were defined - vegetation, impervious surfaces, and soil. Vegetation consists of all plants with chlorophyll. Impervious surfaces are mainly pavements (e.g. roads, highways and streets), building roofs, or any material which restrict water to infiltrate the ground. Soil contains both soil cover and dry vegetation.

\subsection{Validation}

\subsubsection{OLCI Global Vegetation Index}

OLCI Global Vegetation Index (OGVI) or the Fraction of Absorbed Photosynthetically Active Radiation (FAPAR) is one of the Level-2 geophysical products of Sentinel-3 OLCI. Similar to common vegetation indices, OGVI is an indicator of the abundance and productivity of healthy vegetation. Similar to Level-1 products, it has a spatial resolution of 300 meters, and its pixel values have a range of 0 (no vegetation) to 1 (dense vegetation)

To validate the output of the linear spectral unmixing, a validation set consisting of well-distributed points throughout the Sentinel-3 image were randomly selected. The extracted relative abundance of vegetation and OGVI values from the selected pixels were regressed against one another and its coefficient of determination $\left(\mathrm{R}^{2}\right)$ was calculated.

\subsubsection{PlanetScope Imagery}

Launched in 2014, PlanetScope is a commercial satellite constellation that acquires daily imageries of the Earth's surface with a spatial resolution of 3-5 meters and a spectral resolution of 4 bands (i.e. blue, green, red, and near-infrared). Because of its high spatial resolution, recent studies have used PlanetScope images in validating land use and land cover maps generated using moderate-resolution images (Ha, Tuohy, Irwin, \& Tuan, 2018; Mishra, Rai, \& Rai, 2019). 
A PlanetScope Analytic Ortho Tile was acquired from PlanetLabs (https://www.planet.com/) for the validation of the resulting LSU classified images. Pixel-based supervised classification was performed using Maximum Likelihood Algorithm to classify the image into three general land cover classes (vegetation, bare soil, and built-up). Prior to classification, the image was radiometrically calibrated and atmospherically corrected (Fig. 5) to convert digital numbers to bottom-of-atmosphere reflectance using Quick Atmospheric Correction algorithm available in ENVI 5.2.
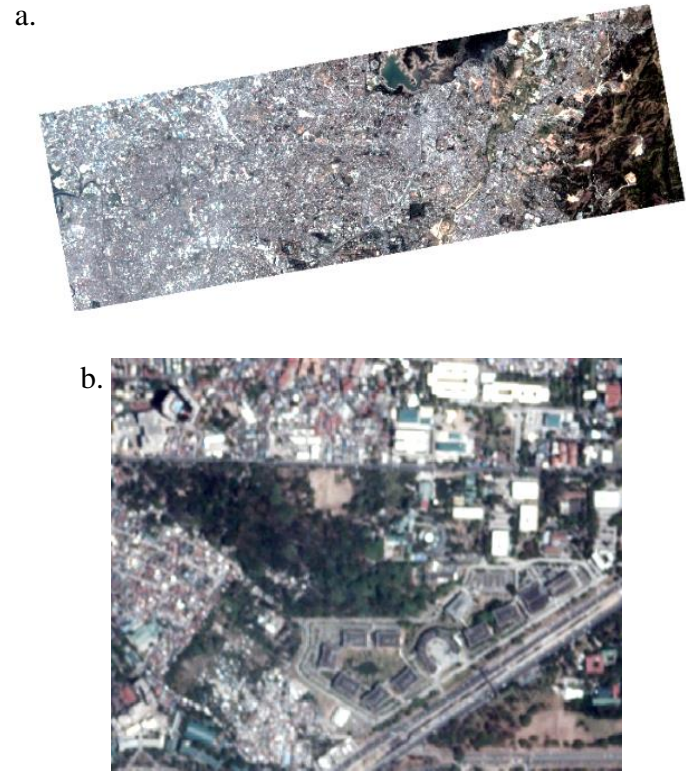

Figure 5. (a) Radiometrically-calibrated PlanetScope truecolor image of a portion of Metro Manila acquired on 23 March 2019 and (b) Sample subset of the image which consists of general land cover classes (vegetation, soil, builtup)

A fishnet with grid size of $300 \mathrm{~m} \times 300 \mathrm{~m}$ was generated from the pixels of the Sentinel-3 image. For each grid, PlanetScopederived vegetation percent cover was calculated by dividing the total vegetation area with the total area inside the grid. A welldistributed set of validation points consisting of grids with varying vegetation coverage were randomly selected within the extent of the PlanetScope image. The relative abundance of vegetation calculated from Sentinel-3 image and the estimated percent cover derived from PlanetScope image were extracted for each validation sample. Linear regression analysis was performed to determine the coefficient of determination $\left(\mathrm{R}^{2}\right)$ between the two datasets.

Table 1 . Summary of satellite images used in this study

\begin{tabular}{|c|c|c|c|}
\hline $\begin{array}{l}\text { Satellite } \\
\text { Imagery }\end{array}$ & $\begin{array}{l}\text { Acquisition } \\
\text { Date }\end{array}$ & $\begin{array}{c}\text { Spatial } \\
\text { Resolution }\end{array}$ & Purpose \\
\hline $\begin{array}{l}\text { Sentinel-3 } \\
\text { OLCI }\end{array}$ & \multirow{2}{*}{$\begin{array}{c}25 \text { April } \\
2019\end{array}$} & \multirow{2}{*}{$\begin{array}{c}300 \\
\text { meters }\end{array}$} & Unmixing \\
\hline $\begin{array}{l}\text { Sentinel-3 } \\
\text { OGVI }\end{array}$ & & & Validation \\
\hline PlanetScope & $\begin{array}{l}23 \text { March } \\
2019\end{array}$ & 3 meters & Validation \\
\hline
\end{tabular}

\subsection{Land Surface Temperature Layer}

Landsat-derived land surface temperature (LST) layer of Metro Manila acquired on 5 February 2019 was downloaded from Climate Engine (CE), a free open-source web application that aids users in processing, visualizing, and downloading remote sensing datasets and gridded meteorological data for environmental monitoring (https://app.climateengine.org/).

\section{RESULTS AND DISCUSSION}

\subsection{Spatial Distribution of Fractional Cover}

The relative abundances of vegetation, impervious materials, and soil in the study area were derived using Linear Spectral Unmixing method. It is observed that higher fractions of impervious class were found in most cities of Metro Manila, while higher fractions of vegetation were associated with forests, parks, and green spaces (e.g. UP Diliman and La Mesa Ecopark in Quezon City). Similarly, higher fraction values of soil were mostly located in the agricultural areas which are outside of Metro Manila (e.g. provinces north and south of Metro Manila) (Fig. 6).

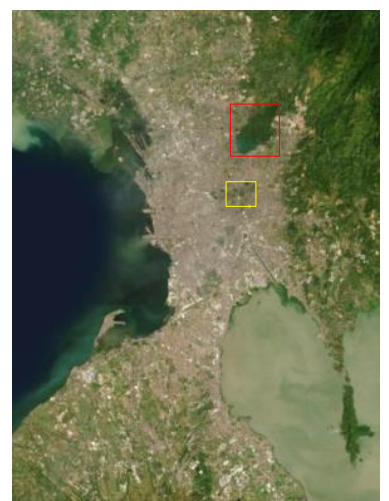

a. True Color Image

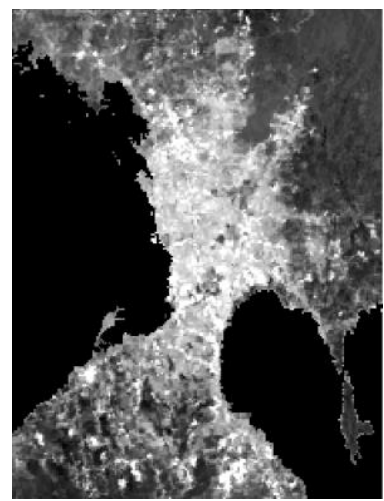

c. Impervious surface

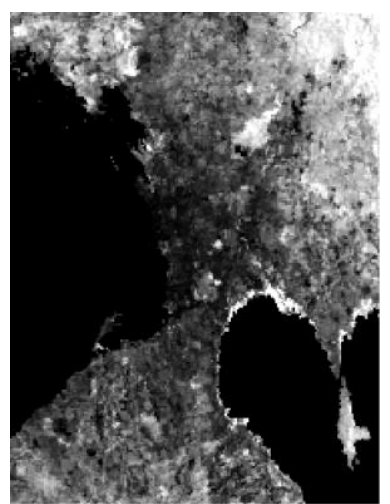

b. Vegetation

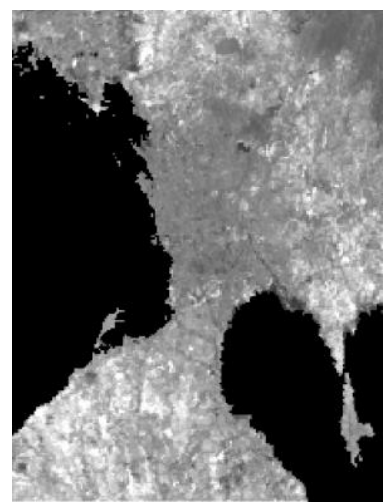

d. Soil
Figure 6. True-color image of the study area showing La Mesa Ecopark (red box) and UP Diliman (yellow box) (a). Resulting fraction images of vegetation (b), impervious (c), and soil (d) from Linear Spectral Unmixing of Sentinel-3 Image. Dark color represents higher abundance while bright color represents lower abundance values.

\subsection{Comparison between the relative abundances derived from Sentinel-3 image and vegetation cover mapped from PlanetScope image}

The validation points were used to assess the difference in pixel values of vegetation between a higher spatial resolution image and the resulting vegetation fraction from Sentinel-3 image. Both the scatter plots (Figs. 7 and 8) between the vegetation fraction cover estimated by LSU method with the calculated percent cover from PlanetScope image and the values from OGVI 
product show a strong agreement, with 0.836 and 0.984 as the coefficient of determination values, respectively.

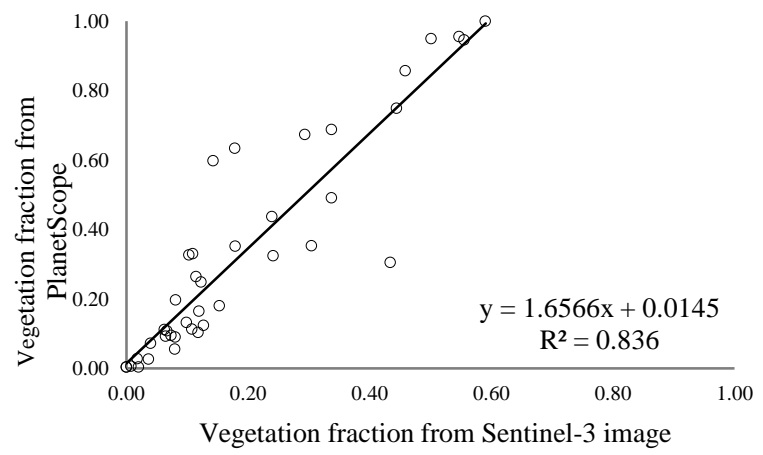

Figure 7. Validation of vegetation fraction estimated from spectral unmixing with those of computed from the PlanetScope image

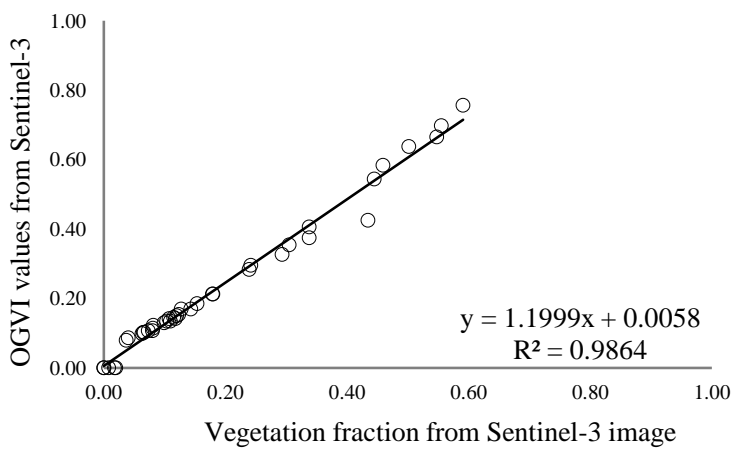

Figure 8. Vegetation fraction estimated from spectral unmixing compared with values from OGVI product of Sentinel-3

\subsection{Relationship between LST and fraction images}

The Land Surface Temperature of Metro Manila in February 2019 ranged from $23 \mathrm{C}$ to $43.14 \mathrm{C}$. It is apparent that there is a temperature difference between inside and outside of Metro Manila. In general, the majority of cities in Metro Manila experience warmer temperatures while the provinces outside of Metro Manila experience relatively colder temperatures (Fig. 9).

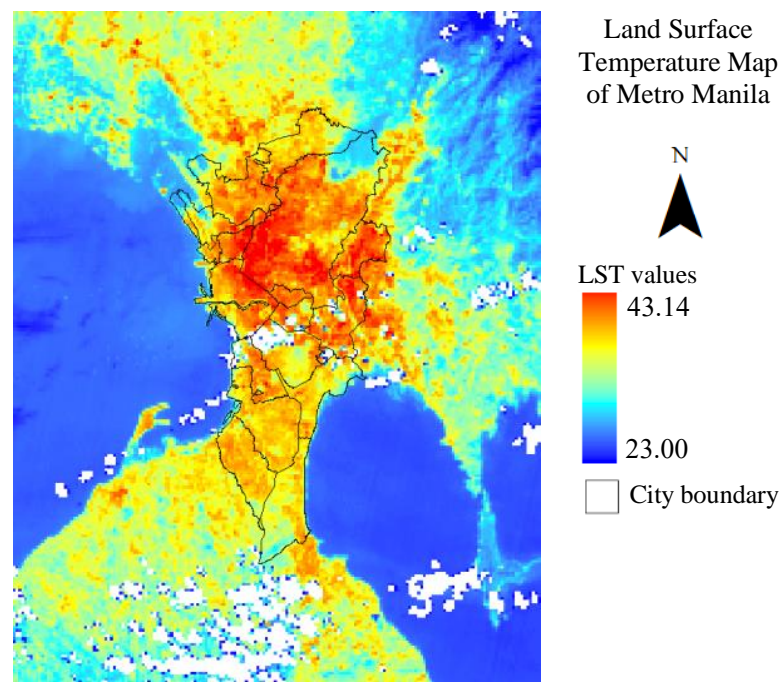

Figure 9. Land Surface Temperature Map of Metro Manila in February 2019. Red areas are warmer regions while blue areas represent the colder regions. Clouds are masked in the image. (Source: Climate Engine)

Likewise, the relationship between the LST values and the fraction images of vegetation, impervious surfaces, and soil were examined through correlation analysis (Fig. 10).
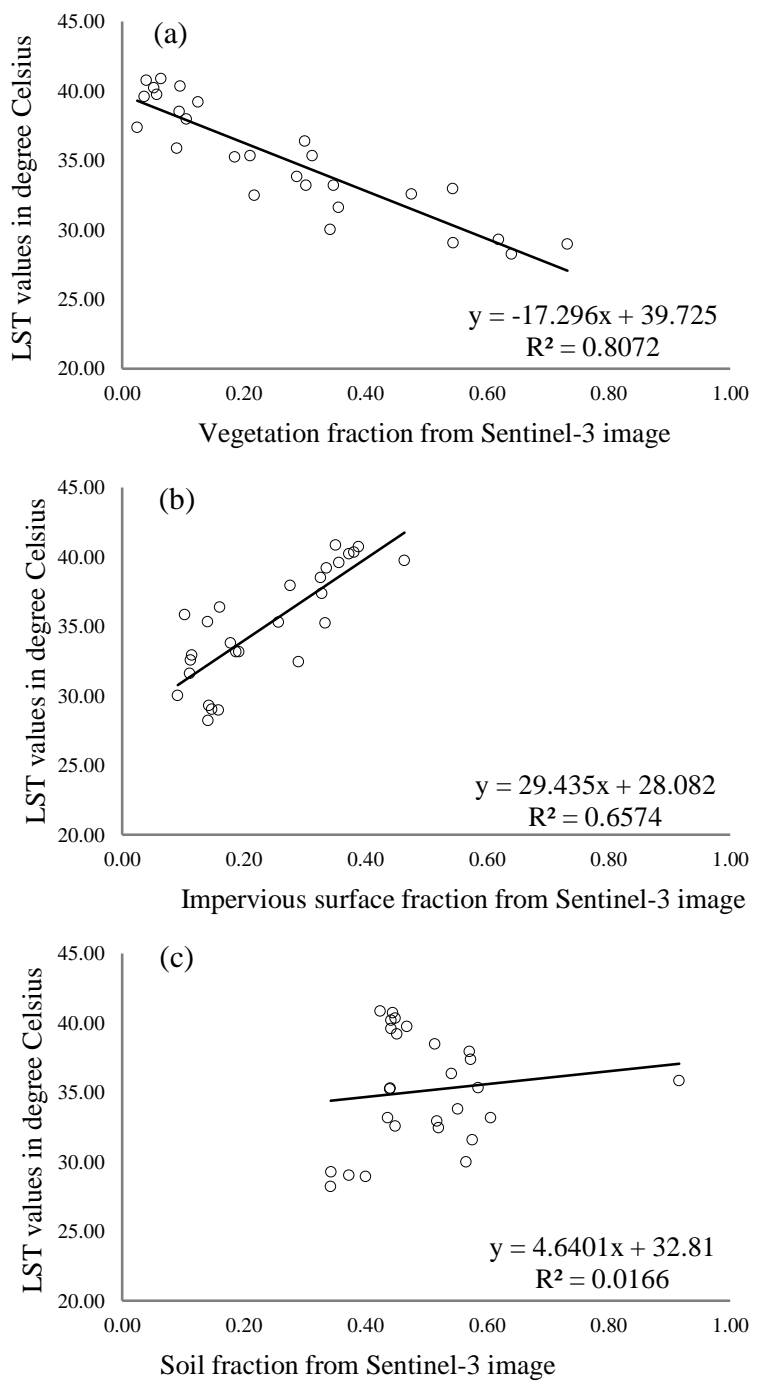

Figure 10. Relationships between LST and relative abundances of vegetation (a), impervious surfaces (b), and soil (c). Fraction images (x-axis) range from 0 to 1 while LST values (y-axis) are expressed in degree Celsius

It is evident that LST values have a negative correlation with the vegetation fraction (Fig. 10a). This means that the higher the vegetation cover has in an area, the lower its surface temperature. Also, there is a significant positive relationship between the LST values and the fraction of impervious materials in the study area (Fig. 10b) which can explain the effect of these materials to the increase of LST in the area. Soil, on the other hand, shows no significant relationship with the LST values $\left(\mathrm{R}^{2}=0.0166\right)$ (Fig. 10c).

\subsection{Zonal Statistics}

The zonal statistics tool is used to calculate statistics of raster values in each user-defined zone. The zones are defined by a different dataset provided by the user. This is commonly used in the analysis and comparison of different areas with well-defined boundaries. In the case of this study, zonal statistics was applied to the LST, and percent cover of vegetation, impervious surface, 
and soil in Metro Manila (for larger scale) and Quezon City (for smaller scale). The calculated statistic was the mean and the boundaries used for each zone were city and barangay boundaries for Metro Manila (Fig. 11a) and Quezon City (Fig. 11b), respectively. The computed mean for each zone was stored in the feature's attribute table which was used in the visualization.

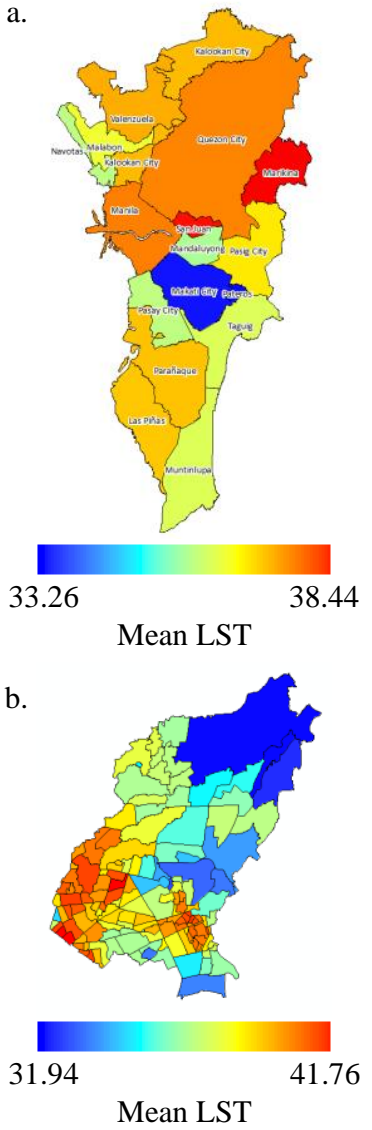

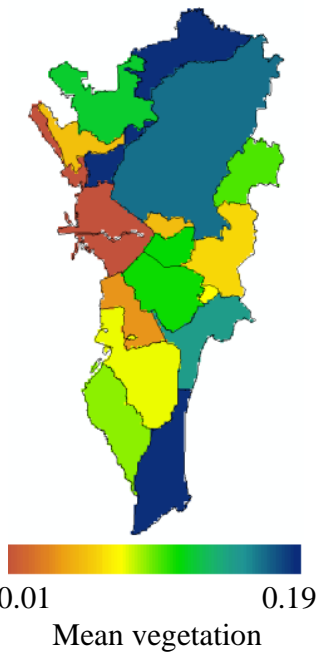
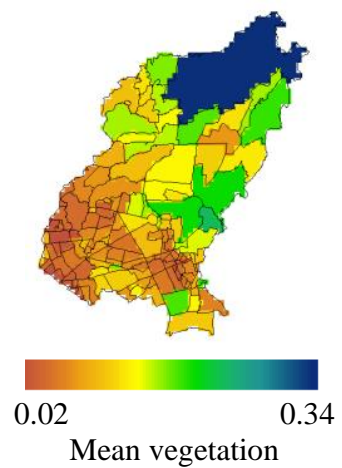
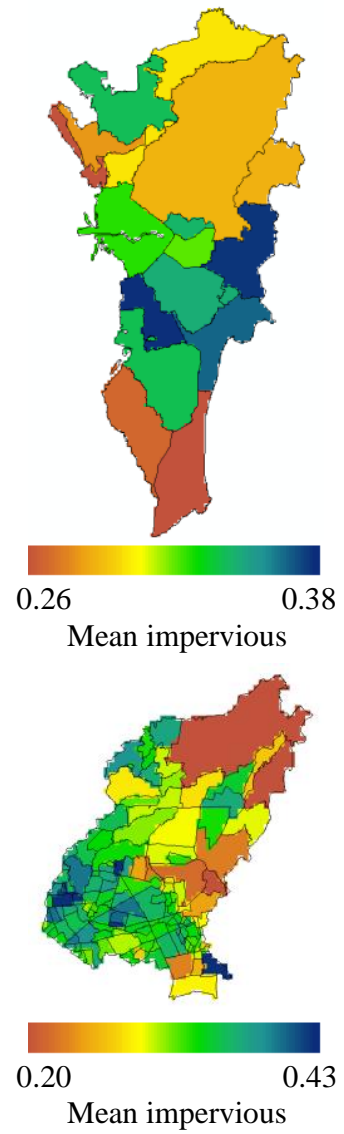
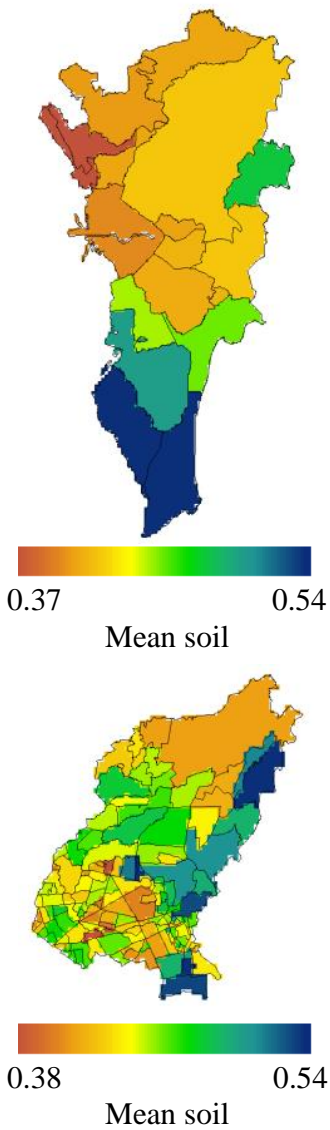

Figure 11. Mean land surface temperature, vegetation, impervious surface, and soil for each city in Metro Manila (a) and for each barangay in Quezon City (b)

\subsubsection{Per-City Analysis}

It can be identified from this study that the cities with the highest land surface temperature on 5 February 2019 were Marikina City $\left(38.44{ }^{\circ} \mathrm{C}\right)$ and San Juan City $\left(38.36{ }^{\circ} \mathrm{C}\right)$ while the lowest mean LST were obtained in the municipality of Pateros $\left(33.26^{\circ} \mathrm{C}\right)$, and Navotas City $\left(33.77{ }^{\circ} \mathrm{C}\right)$ (Fig. 11a; Table 2). Makati City was excluded in the comparison since the hottest portions of the city were covered by clouds during the satellite image acquisition, thus resulting to a significant decrease in mean surface temperature. Although a strong negative correlation was established between the resulting vegetation fraction and LST, it was observed that the lowest mean vegetation proportions were calculated in the cities of Navotas (0.01) and Manila (0.05) which have an average LST of $33.77^{\circ} \mathrm{C}$ and $37.19^{\circ} \mathrm{C}$, respectively. Meanwhile, the highest mean impervious surface proportions were found to be in Pasay City (0.38) and Pasig City (0.38) which are relatively cooler, having an LST of $36.35^{\circ} \mathrm{C}$ and $37.37^{\circ} \mathrm{C}$, respectively. This could imply that although vegetation and builtup cover are both highly correlated with LST, there are other conditions that could intensify the surface temperature experienced by Metro Manila cities. Some factors such as city scale, thermal properties of the building and street materials used (Priyadarsini, Hien, \& David, 2008) urban geometry (e.g. building density, aspect ratio) and orientation, and anthropogenic heat emissions should be considered in order to more accurately identify the possible causes of increasing temperature in each city in Metro Manila. Moreover, it is evident that some of the coastal cities (i.e. Navotas City, Pasay City, Taguig City, and Muntinlupa City) have lower surface temperatures compared to most of the inland cities in Metro Manila. This could be because of the cooling effect of surrounding water bodies due to evapotranspiration (Sun, Chen, Chen, \& Lü, 2012).

Table 2. Mean values of vegetation, impervious surface, soil and LST calculated over the cities of Metro Manila

\begin{tabular}{lcccc}
\hline & $\begin{array}{c}\text { Mean } \\
\text { vegetation }\end{array}$ & $\begin{array}{c}\text { Mean } \\
\text { impervious }\end{array}$ & $\begin{array}{c}\text { Mean } \\
\text { soil }\end{array}$ & $\begin{array}{c}\text { Mean } \\
\text { LST }\end{array}$ \\
\hline Kalookan & 0.182 & 0.322 & 0.432 & 36.26 \\
Las Pinas & 0.115 & 0.296 & 0.543 & 36.08 \\
Makati & 0.128 & 0.357 & 0.432 & 35.39 \\
Malabon & 0.088 & 0.306 & 0.402 & 34.95 \\
Mandaluyong & 0.130 & 0.338 & 0.435 & 36.53 \\
Manila & 0.053 & 0.342 & 0.423 & 37.19 \\
Marikina & 0.122 & 0.310 & 0.489 & 38.44 \\
Muntinlupa & 0.194 & 0.262 & 0.535 & 34.48 \\
Navotas & 0.015 & 0.289 & 0.365 & 33.77 \\
Paranaque & 0.105 & 0.352 & 0.506 & 36.12 \\
Pasay & 0.075 & 0.383 & 0.463 & 36.35 \\
Pasig & 0.094 & 0.381 & 0.440 & 37.37 \\
Pateros & 0.104 & 0.357 & 0.435 & 33.26 \\
Quezon & 0.166 & 0.312 & 0.441 & 37.15 \\
San Juan & 0.087 & 0.355 & 0.430 & 38.36
\end{tabular}




\begin{tabular}{lllll} 
Taguig & 0.154 & 0.373 & 0.469 & 35.07 \\
Valenzuela & 0.135 & 0.353 & 0.427 & 36.47 \\
\hline
\end{tabular}

\subsubsection{Per-Barangay Analysis}

In Quezon City, the mean vegetation and mean impervious maps for each barangay show that they have a strong negative correlation. Barangays in the southern portion of the city have low mean vegetation values and high mean impervious values since this is where most of the residential areas in the city are located. The houses are built closely and have little or no vegetation cover present. These areas also pose high mean LST values, which coincides with the literature (Kaufmann et al., 2003) that areas with no vegetation and are covered with impervious surfaces cause a rise in temperature. The mean LST map (Fig. 11b) reveals that in these areas, their mean LSTs range from $40{ }^{\circ} \mathrm{C}$ up to the maximum mean $\operatorname{LST}\left(41.76^{\circ} \mathrm{C}\right)$ in the city. Some of these barangays are Lourdes, Sikatuna Village, Salvacion, Veterans Village, etc. The results are different at the northern portion of Quezon City with temperature ranging from $31.94{ }^{\circ} \mathrm{C}$ to $36{ }^{\circ} \mathrm{C}$. This is where most of the green spaces in the city are located. Expectedly, these areas have high mean vegetation values and low values in the mean impervious map. Some of these areas are composed of grassland up to wide tree cover. Barangays with moderately high temperature ranging from $37^{\circ} \mathrm{C}$ to $39^{\circ} \mathrm{C}$ are in the areas with infrastructures that have less vegetation surrounding the area.

\section{CONCLUSION}

Considering the increasing rate of urbanization in recent decades, frequent monitoring over a large area is urgently needed. This study demonstrates the use of remote sensing technologies in identifying the land cover composition in an area and recognizing its effect in the observed surface temperature. To achieve this, Linear Spectral Umixing method was applied to identify the composition of various surface covers in Metro Manila using the image acquired by the recently-launched Sentinel-3 satellite. This particular observation satellite offers a daily image acquisition to support environmental monitoring. The results demonstrate that Metro Manila is characterized as a highlyurbanized area in the country with a high percentage of impervious surfaces such as concrete, asphalt, and building roofs. This particular surface cover is associated with the observed high temperature in the area. Analyzing the relationships between the land surface temperature and percentages of land cover in a city highlight the importance of vegetation and green spaces in an urban setting. As shown in the results, warmer places mostly consist of impervious surfaces while those with vegetation cover are associated with lower temperature. Unfortunately, only a significantly low percentage of vegetation is present in Metro Manila. This appears to be one of the biggest challenges for planners and developers in their effective urban management.

However, impervious surfaces are not the only factor for the increase in temperature in a city. Other aspects such as proximity to water bodies, building and road geometry, and construction materials should be considered in proper urban planning. This can be observed with the results of this study that some cities in Metro Manila which have the highest percentages of impervious surfaces or with the lowest vegetation cover are not the warmest cities.

For future studies, the authors recommend the implementation of other sub-pixel classification methods using Sentinel-3 satellite imagery in order to classify impervious surfaces into specific urban surface materials (i.e. metallic roofs, concrete pavement, asphalt pavement). Furthermore, the relationship between land surface temperature and the thermal radiative properties of different construction materials should be investigated.

\section{ACKNOWLEDGEMENTS}

This research is funded by the Philippine Council for Industry, Energy and Emerging Technology Research and Development Department of Science and Technology (PCIEERD - DOST) under the Geospatial Assessment and Modelling of Urban Heat Islands in Philippine Cities (Project GUHeat) with Project No. 4028, 2019. Utmost acknowledgement is given to Planet Labs for providing free access to high-resolution PlanetScope images that were utilized in this study.

\section{REFERENCES}

Aggarwal, N., \& Dutta, M. (2016). Comparative Analysis of Pixel-Based and Object-Based Classification of High Resolution Remote Sensing Images - A Review. International Journal of Engineering Trends and Technology, 38(1). https://doi.org/10.14445/22315381/IJETT-V38P202

Bai, L., Lin, H., Sun, H., Mo, D., \& Yan, E. (2012). Spectral Unmixing Approach in Remotely Sensed Forest Cover Estimation: A Study of Subtropical Forest in Southeast China. Physics Procedia, 25, 1055-1062. https://doi.org/10.1016/j.phpro.2012.03.199

Cornara, S., Pirondini, F., \& Palmade, J. L. (2017). Sentinel-3 coverage-driven mission design : Coupling of orbit selection and instrument design. Acta Astronautica, 140, 439-451. https://doi.org/10.1016/j.actaastro.2017.08.017

Ha, T. V, Tuohy, M., Irwin, M., \& Tuan, P. V. (2018). Monitoring and mapping rural urbanization and land use changes using Landsat data in the northeast subtropical region of Vietnam. The Egyptian Journal of Remote Sensing and Space Sciences. https://doi.org/10.1016/j.ejrs.2018.07.001

Kaufmann, R. K., Zhou, L., Myneni, R. B., Tucker, C. J., Slayback, D., Shabanov, N. V, \& Pinzon, J. (2003). The effect of vegetation on surface temperature: A statistical analysis of NDVI and climate data. Geophysical Research Letters, 30. https://doi.org/10.1029/2003GL018251

Maktav, D., Erbek, F. S., \& Jürgens, C. (2005). Remote sensing of urban areas. International Journal of Remote Sensing, 655659. https://doi.org/10.1080/01431160512331316469

McCoy, R. M. (2005). Field Methods in Remote Sensing. New York London: The Guilford Press.

Mishra, P. K., Rai, A., \& Rai, S. C. (2019). Land use and land cover change detection using geospatial techniques in the Sikkim Himalaya , India. The Egyptian Journal of Remote Sensing and Space Sciences. https://doi.org/10.1016/j.ejrs.2019.02.001 
Priyadarsini, R., Hien, W. N., \& David, C. K. W. (2008). Microclimatic modeling of the urban thermal environment of Singapore to mitigate urban heat island. 82, 727-745. https://doi.org/10.1016/j.solener.2008.02.008

Ragragio, J. M. (2000). The case of Metro Manila, Philippines.

Sibaruddin, H. I., Shafri, H. Z. M., Pradhan, B., \& Haron, N. A. (2018). Comparison of pixel-based and object-based image classification techniques in extracting information from UAV imagery data Comparison of pixel-based and object-based image classification techniques in extracting information from UAV imagery data. Earth and Environmental Science, 169. https://doi.org/10.1088/1755-1315/169/1/012098

Sun, R., Chen, A., Chen, L., \& Lü, Y. (2012). Cooling effects of wetlands in an urban region: The case of Beijing. Ecological Indicators: Integrating Sciences for Monitoring, Assessment and Management, 20. https://doi.org/10.1016/j.ecolind.2012.02.006

Tiangco, M., Lagmay, A. M. F., \& Argete, J. (2008). ASTERbased study of the night-time urban heat island effect in Metro Manila. International Journal of Remote Sensing. https://doi.org/10.1080/01431160701408360

Yang, J., \& He, Y. (2017). Automated mapping of impervious surfaces in urban and suburban areas : Linear spectral unmixing of high spatial resolution imagery. International Journal of Applied Earth Observations and Geoinformation, 54, 53-64. https://doi.org/10.1016/j.jag.2016.09.006 